\title{
CORRIGENDUM
}

\section{Statin-induced expression change of INSIGI in lymphoblastoid cell lines correlates with plasma triglyceride statin response in a sex-specific manner}

E Theusch, K Kim, K Stevens, JD Smith, Y-DI Chen, JI Rotter, DA Nickerson and MW Medina

The Pharmacogenomics Journal (2016) 16, 301; doi:10.1038/tpj.2016.30

Correction to: The Pharmacogenomics Journal advance online publication, 1 March 2016; doi:10.1038/tpj.2016.12

In the published version of this article, the funding statement was omitted. The full statement appears below:

This work was supported by NHLBI U19 HL069757, NHLBI R01 HL104133, AHA 12POST10430005, NHLBI T32 HL098057 and the
NIH Pharmacogenomics Research Network (PGRN) RNA Sequencing Project (GM61390). This work used the Vincent J. Coates Genomics Sequencing Laboratory at UC Berkeley, supported by NIH S10 Instrumentation Grants S10RR029668 and S10RR027303. The funders had no role in study design, data collection and analysis, decision to publish or preparation of the manuscript.

The authors regret the error. 